\title{
Dietary Vitamin D Knowledge of Sub-Saharan African Men Who Migrate to Australia
}

\begin{abstract}
Keywords: Men's health; Vitamin D; African; Perceptions; Migration
Abstract

Background: Vitamin D deficiency is as a global health problem with high prevalence in specific ethnic groups. Changes in dietary practices have occurred in African migrants upon migration to western countries. Men show little to no awareness of their health, with many unable to adequately meet their Recommended Daily Intake (RDI) of vitamin D. This study aims to explore the knowledge around vitamin $D$, changes in dietary intake practices of vitamin $D$ and whether it is seen important among sub-Saharan African men who have migrated to Australia.
\end{abstract}

Methods: A qualitative research design was used to bette understand the knowledge and behaviors of 24 sub-Saharan African men who reside in Melbourne, Australia. A mixed group of countries of origin were included with varying religiosities and practices. Through in-depth interviewing, three themes were identified using thematic analysis of interviews. Demographic data were also collected.

Results: Three broad themes evolved from the study. These themes include the impact of migration on food culture which may have negatively affected vitamin D intake, the impact of masculinity and cultural norms which may have led to vitamin $D$ health understandings and, the impact of educational awareness on overall vitamin D and health status in the sub-Saharan African male population.

Conclusion: This study revealed that majority of sub-Saharan African men were unaware of the sources of dietary vitamin D. Migration to western countries with western diets, masculine ideologies and a lack of educational awareness has led many of these subSaharan African migrant men to become disconnected from their dietary vitamin $D$ requirements and ultimately their vitamin D health status.

\section{Introduction}

Vitamin D deficiency is a major health problem that affects more than 1 billion people worldwide [1]. In the skin,it is produced from the conversion of cholesterol (7-dehydroxycholesterol) to cholecalciferol (Vitamin D3), through the action of UVB rays from sunlight exposure on skin. It enters the circulation and travels to the liver where it is first hydroxylate to the major circulating metabolite and then requires further hydroxylation in the kidneys to form the biological active form 1,25-dihydroxyvitamin $\mathrm{D}\left(1,25(\mathrm{OH})_{2} \mathrm{D}\right)$ and this is what stimulates calcium absorption via the intestinal tract [2]. It is also produced from foods mostly of animal origin (fish, liver and egg yolks), fortified dairy food and cereals, and UVB irradiation of the ergo sterol in plants and fungi (mushrooms) [3]. Vitamin D is now understood to be linked with several non-musculoskeletal conditions such as risk of cardiovascular disease [4], onset of diabetes and some cancers such as prostate cancer $[5,6]$. Furthermore, the link with depression has also been studied extensively with a recent systematic review and meta-analysis of adult cohort studies reporting a significant increased risk of depression with low levels of vitamin

\section{Journal of} Nutrition and Health

\author{
Hassan A, Wollersheim D, Susanto NH, Batra M, \\ Itsiopoulos $\mathbf{C}$ and Erbas B* \\ La Trobe University, Australia
}

*Address for Correspondence

Erbas B, Professor, School of Pyschology and Public Health, La Trobe University, Bundoora, 3086, Victoria, Australia, Tel: +61 39479 5657, Fax: +61 39479 1783, E-mail: b.erbas@latrobe.edu.au

Submission: September 3, 2018

Accepted: November 6, 2018

Published: November 9, 2018

Copyright: (๑) 2018 Hassan A, et al. This is an open access article distributed under the Creative Commons Attribution License, which permits unrestricted use, distribution, and reproduction in any medium, provided the original work is properly cited.

$\mathrm{D}[7]$.

African migrant subpopulations in the United States, European countries and Australia have the poorest vitamin D status when compared to African migrants in the African countries [1]. Migration to western countries with lower UVB rays, advanced infrastructure and sedentary lifestyles predisposes dark skinned migrants to vitamin D deficiency. Exposure to sunlight is an important source of synthesizing vitamin $\mathrm{D}$ in the skin as sunlight contains Ultraviolet (UV) radiation [8]. When physiological, environmental and social circumstances prevent adequate sunlight exposure, it is imperative that dietary intake of vitamin $\mathrm{D}$ be maintained to achieve adequate levels of serum 25(OH)D [9]. Changes in dietary practices have occurred in African migrants after resettlement in western countries.

Sub-Saharan Africans migrants are one of the largest growing populations in Australia as evidenced by the increase in the number of South-African born persons in the 2016 census and ranked 8 of the 10 top countries of birth in Australia [10]. For sub-Saharan African migrants, the cultural and social constructs surrounding food is an important aspect of dietary habits following resettlement [11]. Current data indicates a rapid move towards the use of fast-food alternatives and away from their nutritionally rich traditional foods [12]. Dramatic changes in environment and lifestyle along with the inability to read nutritional labels due to low English language literacy have been identified as major factors for vitamin D deficiency in the sub-Saharan African community [13,14].

There is an unequal health outcome between the males and females, due in part, to the amount of effort placed into women's health promotion [15]. The increased prevalence of dietary vitamin D deficiency among dark skin and veiled women, children and the elderly is well documented [16-22]. On the other hand, little attention has been given to sub-Saharan African men's health, dietary habits and health awareness. African migrant men are culturally reliant on their female partners as a source of information regarding their eating habits and their health [23]. They show little to no awareness of their health, with many unable to meet their Recommended Daily Intake (RDI) of vitamin D [22]. This is the first study to explore the knowledge and behaviours on changing dietary patterns, understanding of the 
Citation: Hassan A, Wollersheim D, Susanto NH, Batra M, Itsiopoulos C, et al. Dietary Vitamin D Knowledge of Sub-Saharan African Men Who Migrate to Australia. J Nutri Health. 2018;4(2): 4.

ISSN: 2469-4185

Table 1: Demographic profile of the participants.

\begin{tabular}{|c|c|c|c|c|c|c|c|c|}
\hline ID & AGE & ETHNICTY & RELIGION & NO. OF SIBLINGS & ARRIVAL/BIRTH & EMPLOYMENT & TYPE & HIGHEST EDUCATION \\
\hline \#001 & 19 & Somalia & Islam & 7 & Arrived in 1998 & Waiter and Accountant & PT & B. Accounting \\
\hline \#003 & 18 & Somalia & Islam & 6 & Born in 1997 & No Employment & $\mathrm{N} / \mathrm{A}$ & Year 12 \\
\hline \#005 & 20 & Eritrean & Islam & 3 & Arrived in 2001 & McDonalds & Casual & B. Health Science \\
\hline \#007 & 20 & Kenya & Islam & 8 & Arrived in 1999 & No Employment & $\mathrm{N} / \mathrm{A}$ & B. Accounting \\
\hline \#009 & 29 & Nigeria & Islam & 4 & Arrived in 1996 & Structural Engineer & FT & B. Science/Building Co. \\
\hline \#011 & 26 & Somalia & Islam & 5 & Born in 1989 & Coles & PT & B. International Buss. \\
\hline \#013 & 27 & Ethiopian & Orthodox & 3 & Born in 1988 & Banking Analyst & FT & M. Finance \\
\hline \#015 & 19 & Ethiopian & Islam & 4 & Born in 1996 & No Employment & $\mathrm{N} / \mathrm{A}$ & B. Business \\
\hline \#017 & 19 & Eritrean & Islam & 8 & Born in 1996 & Self Employed & FT & B. Exercise Science \\
\hline \#019 & 21 & Ethiopian & Islam & 3 & Arrived in 1999 & Community Dev. Officer & PT & Diploma in Business \\
\hline \#021 & 23 & Eritrean & Islam & 4 & Born in 1992 & Retail & Casual & M. Occ. Therapy \\
\hline$\# 002$ & 47 & Somalia & Islam & 7 & Arrived in 1998 & Processor & Casual & Cert. 4 in Accounting \\
\hline \#004 & 54 & Somalia & Islam & 6 & Arrived in 1986 & Family Day Care & FT & Cert. 3 in Accounting \\
\hline \#006 & 59 & Eritrean & Islam & 3 & Arrived in 2001 & AMES (Settlements) & Casual & B. Agriculture \\
\hline$\# 008$ & 52 & Kenya & Islam & 8 & Arrived in 1999 & IT Consul./ Travel Agent & PT & M. Business Admin. \\
\hline \#010 & 59 & Nigeria & Islam & 4 & Arrived in 1987 & No Employment & $\mathrm{N} / \mathrm{A}$ & Year 12 \\
\hline \#012 & 48 & Somalia & Islam & 5 & Arrived in 1985 & No Employment & $\mathrm{N} / \mathrm{A}$ & B. Information Tech. \\
\hline \#014 & 56 & Ethiopian & Orthodox & 3 & Arrived in 1988 & Taxi Driver & FT & B. Maths and Physics \\
\hline \#016 & 46 & Ethiopian & Islam & 4 & Arrived in 1988 & PET (dog food company) & Casual & D. Arabic Language \\
\hline \#018 & 51 & Eritrean & Islam & 8 & Arrived in 1987 & Auto Mechanic & FT & B. Banking \\
\hline \#020 & 45 & Ethiopian & Islam & 3 & Arrived in 1999 & Family Day Care & PT & B. Business \\
\hline
\end{tabular}

role of vitamin D and its association with various health outcomes among sub-Saharan African men from various religiosities residing in Melbourne, Australia.

\section{Methods}

\section{Sample}

Convenient sampling methods were employed, and the study was advertised in local language radio and social clubs for the purpose of recruitment. Twenty-four sub-Saharan African males were recruited from countries of origin in Somalia, Ethiopia, Oromo, Eritrea, Kenya and Nigeria. This number was deemed suitable given that very little "new" information came out of the transcripts after we conducted 10 interviews. All participants were 18 years and older. Participants also needed to have resided in their new country for a minimum of 5 years as a good indication of adopting to their new lifestyle. Although, an inability to speak English was an exclusion criterion, we recruited participants if they were comfortable with basic spoken English and relaying their response through the researcher who is of African ancestry (AH). Participants were recruited over a five-week period. For this study we defined masculinity as a marker of masculine ideologies among men has typically socialized as being independent, tough, establishing heterosexual relationships, avoiding emotional expressions early in life and becoming a father [24].

\section{Research methodology}

An exploratory model of research, an ethnographic style of understanding and a constructivist paradigm was used as the philosophical basis for this study. Firstly, an exploratory model of research was used to explore what we know about the sub-Saharan African male community and lack of awareness on the issue of vitamin D deficiency. Secondly, an ethnographic style of understanding was applied to identify customs and values that shape sub-Saharan African men's views towards vitamin D deficiency. Finally, Constructivist paradigm was used as the philosophical basis as it is idiosyncratic and holistic. Demographic data were also collected.

\section{Interviews and data analysis}

Semi-structured, in-depth interviews were conducted face-to-face and a series of questions relating to the participant's understanding of Vitamin D were developed. For example, we focused on questions on participant's knowledge of the benefits of vitamin $\mathrm{D}$, understanding of sun exposure and its impact on vitamin D intake, alternative dietary sources of vitamin $\mathrm{D}$ and how culture affects sun-sourced vitamin $\mathrm{D}$ intake. As this is the first qualitative study on this topic, we developed our questions but were guided by other research too.

The interviews were audio recorded to allow for accurate transcription and improve thematic coding. Thematic analysis was 
Citation: Hassan A, Wollersheim D, Susanto NH, Batra M, Itsiopoulos C, et al. Dietary Vitamin D Knowledge of Sub-Saharan African Men Who Migrate to Australia. J Nutri Health. 2018;4(2): 4.

ISSN: 2469-4185

Table 2: Summary measures of the participants by age, education, employment and migrant status.

\begin{tabular}{|c|c|}
\hline Character & \\
\hline Age & Median 37 , range $18-59$ \\
\hline Number of siblings & Median 5 , range 3-8 \\
\hline $\begin{array}{l}\text { Education } \\
\text { - } \quad \text { Year } 12 \\
\text { - } \quad \text { University level }\end{array}$ & $\begin{array}{c}2(8 \%) \\
22(92 \%)\end{array}$ \\
\hline $\begin{array}{ll} & \text { Employment status } \\
\text { - } & \text { Unemployed } \\
\text { - } & \text { Employed }\end{array}$ & $\begin{array}{c}5(21 \%) \\
19(79 \%)\end{array}$ \\
\hline $\begin{array}{l}\text { Migrant status } \\
\text { - } \quad \text { Migrant } \\
\text { - } \quad \text { Born in Australia }\end{array}$ & $\begin{array}{c}18(75 \%) \\
6(25 \%)\end{array}$ \\
\hline
\end{tabular}

adopted to allow comparisons within and between interviews and emerging themes was identified. A coding frame was developed and two authors (AH and DW) met to discuss themes identified. $\mathrm{N}$ vivo software was used to process the data and once all electronically coded a systematic approach to data analysed was used [25]

\section{Results}

The characteristics of the $n=24$ participants are presented in Table 1 and summary measures by age, education, employment and migrant status in Table 2 . The age ranged from 18 to 59 years with a median of 37 years. A high proportion were university level educated (92\%) and over $79 \%$ were employed either full time or part time. All but one was of the Islamic faith (The other was an Orthodox Christian) and 33\% were from Somalia, 25\% from Eritrea, 25\% from Ethiopia, 8\% from Kenya and $8 \%$ from Nigeria. The qualitative analysis generated three themes; a) the impacts on dietary health (in particular dietary vitamin $\mathrm{D}$ ) due to migration to a new food environment $b$ ) the effect of masculinity and cultural norms on vitamin $\mathrm{D}$ and overall health understandings and c) the influence of education on overall vitamin $\mathrm{D}$ and health status.

\section{Theme 1: Migration to a new food environment}

Population movement from Africa to Australia was an important indicator of a lack of understanding in dietary vitamin $\mathrm{D}$ knowledge. Many men were unable to adapt to their new food environment.

“...most of the people haven't been orientated well with the knowledge of vitamin D and its foods. There is no education. In Africa, most of the people do not worry about the sun but in here [Melbourne] the environment is different. I think people don't know about the consequences of vitamin D, I think people would care if they were educated" (Eritrean, age 51).

"The problem is that our culture, we don't understand when we come to Australia. There is no knowledge in people. Some people need to tell us about vitamin D" (Ethiopian, age 46).

When asked which foods were rich in vitamin $\mathrm{D}$, a large majority of the participants were unaware of which foods were rich in vitamin D.

"No. I thought I did, I use to think vegemite was but I would put it down to lack of education. I know about the ABC but D didn't get much airplay growing up" (Ethiopian, age 27).
"No. I do not know. I do not know about vitamin D so I will not know about the foods. I do not know, I would probably say potatoes. It comes to my mind and I think potatoes give me strong bones" (Nigerian, age 59).

Seeking knowledge on all aspects of vitamin D and vitamin D deficiency was not an important priority for many upon resettlement because they didn't believe it was important for their health.

"When people move to Australia they need to build their family and settle down [rather] than they focus on their health. Unless they are sick, they will not go to their doctors. I think Africans are busy raising their family and don't care about themselves" (Somalian, age $56)$.

"Africans stick to their culture and don't integrate with the wider community. Self-improvement is not seen in the African culture. The media is currently promoting healthy eating and if the African community as a whole were more receptive to that message of healthy eating a diet, than it would be better for them. I feel like the older African people are stuck in their culture" (Eritrean, age 23)

\section{Theme 2: Masculinity and cultural upbringings}

Masculinity and cultural norms were important components to men's mindset. When asked who they felt were at risk of vitamin D deficiency they were quick to note their female counterparts as being more susceptible to vitamin $\mathrm{D}$ deficiency then themselves.

"I would say east African women. Culturally they tend to stay at home more, whereas with other ethnic groups, they tend to go out to playgroups and parks and culturally in my perspective, east African women do not leave the house compared to other nationalities. It is that age group [20 years and older] that they are busy with either work or chores" (Ethiopian, age 21).

They also believed that because men were more active, were not as covered by clothing, and less home orientated, they did not need to be as aware of their vitamin D levels, compared to women.

"I think it's a cultural thing. I think men are more active and I feel they are out in the sun a lot more and I feel as if women are a lot more inside, cooking, looking after the children. So I feel women are at the greatest risk" (Ethiopian, age 27).

"I am talking about Muslim women because of their religious reasons. They are covered" (Somalian, age 56).

Those aged fifty and over were all aware of their vitamin D status. Being consciously aware of their deteriorating health status has led this cohort of men to seek advice from their general practitioner.

"Yes I found out about two months ago when I felt it and I needed it. I had the same problem a long time ago. I asked my doctor for a blood test because I was suspecting that I had vitamin D deficiency" (Eritrean, age 51).

"Not yet, I am ok. I go to the doctor every year to check up. I do not want to be a burden of the kids. I am not vitamin D deficient" (Ethiopian, age 56).

However, being vigilant about vitamin $\mathrm{D}$ was not apparent in the younger cohort. 
"I wouldn't have a clue; I haven't been to the doctors in ages. The last time I went to the doctors was four to five weeks ago, when I had a sore throat" (Kenyan, age 20).

"No I'm not. I am assuming. I spend so much time in the sun that I do not think I need it. Generally, I never had a blood test to check for my wellbeing" (Ethiopian, age 21).

\section{Theme 3: Educating the sub-Saharan African male community}

Lack of dietary vitamin D educational awareness was common and identified as a barrier by participants when asked "Do you think the sub-Saharan African community in Australia is adequately informed about dietary vitamin $\mathrm{D}$ and vitamin $\mathrm{D}$ deficiency and why?" Some believed a lack of education of vitamin D and its foods based on the transition process from Africa to Australia and their educational upbringing in their home country.

"It's the level of education and the lifestyle most black people live. The issue of vitamin D is not there back home in Africa. Most Africans are stuck in their culture and their dietary lifestyle has not changed from when they were back home. Most stay indoors as well" (Eritrean, age 55).

"They are not well educated about it. Most of them have the perception that if they stay in the sun it will be enough vitamin $D$ but I think it has a lot more to do with your diet as well" (Kenyan, age 20).

Along with education, they stated language difficulties, access to educational opportunities and a general lack of care towards dietary vitamin Das explanations to why many men lack awareness and are ill-informed of their dietary and vitamin D status.

"There is a lack of language. We need to have people who speak the same language, who can talk about vitamin D deficiency and to explain to them what is good about it. We need to use our own people to explain to them. People listen to their own people. If they understand they follow, if they don't they don't follow" (Somalian, age 54).

"I think it is the same for any community. I do not think they are adequately informed. I don't think anyone is though" (Eritrean, age 23).

\section{Discussion}

This is the first study to explore the knowledge of dietary vitamin D among sub-Saharan African men who migrated to Australia, a region very different to their home country. The findings suggest that sub-Saharan African men were unaware of the concepts of dietary vitamin D. Migration to western countries with western diets, masculine ideologies and a lack of educational understanding has led many of these sub-Saharan African men to become disconnected towards their dietary vitamin $\mathrm{D}$ awareness and ultimately to their vitamin D health status, especially among younger men which is an "at risk" group over time.

Our findings suggest that sub-Saharan African men were not dietary vitamin $\mathrm{D}$ conscious. In fact, several of the men did not practice good dietary habits, choosing to eat ready-made meals with little nutritional content if their spouse or mother did not prepare meals for them. Migration to a new way of living and a lack of education were their main reason for a lack of good dietary habits. Furthermore, we found that many of the participants believed living in Africa was a healthier choice for their overall vitamin D health status than living in Australia. Most participants understood that seasonal difference of lower UVB rays in Australia compared to their own country in Africa, was one of the major factors contributing to their lack of exposure to the sun and their lack of dietary vitamin D knowledge. Many participants emphasized the consistent weather in Africa, which has the one season consisting of hot conditions was far better for them than the four seasons of Melbourne. In addition, dietary awareness and food knowledge would not be on their agenda unless they were studying nutrition or any other food or health related courses.

Our finding on migrant men being unaware and uninformed of their dietary food choices upon migration to new food environments are like other studies. For instance, a study conducted in the US discussed the lack of knowledge among Korean immigrants about healthy food choices available in the US [26]. Similarly, this study also points to cultural issues affecting food choices. For example, immigrant women being responsible for cooking and nutrition and men being dependent on the women for food choices. Similarly, another study in Pennsylvania [27], exploring the effects of acculturation among Hispanic workers found that the workers were unaware and uninformed about American foods available. This is mainly due to lack of language and transport as highlighted in the same study. The same study also stated that dietary acculturation significantly affects the food choices. However, results in the latter study were not ascribed by gender.

Understanding how the masculine ideology affects these men's health is an essential first step towards providing effective care for these men. Our finding is also in keeping with recent research on men's health and further reinforces what is known within the literature about the neglect men express towards their health $[24,28,29]$. For example, one participant described men as bulletproof and explained that men felt it was a sign of weakness to be concerned about trivial health issues. Further empirical research examining the health seeking behavior of men has also shown that men who embrace more traditional beliefs were found to have more negative health seeking behaviors [30,31]. Policy makers and health program designers should consider this ideology in creative ways to improve health knowledge and awareness among men. Our findings also suggest that older participants were more vigilant of their vitamin D status and were generally aware of their general health compared to younger participants but this is in contrast with another study where older people reported to have lower levels of awareness of Vitamin D deficiency [32]. However, differences in the study designs limits our comparison between the two and probes further investigation.

Limited opportunities in understanding the nutrition needs of regions such as Australia also emerged. Participants felt that the sub-Saharan African man did not have the same health awareness and knowledge like the general community. Many felt that health literacy programs did not target their communities. The African male community was not absorbing important health information as English was not their native language. Our finding on the importance of health education in increasing health knowledge and 
Citation: Hassan A, Wollersheim D, Susanto NH, Batra M, Itsiopoulos C, et al. Dietary Vitamin D Knowledge of Sub-Saharan African Men Who Migrate to Australia. J Nutri Health. 2018;4(2): 4.

ISSN: 2469-4185

improving language within the migrant population was consistent with previous work which has also listed language and health literacy as vital elements in developing health awareness and knowledge among migrants [33]. In line with the same finding, another study identified that health promotion programs are inadequate and do not necessarily meet the needs of culturally and linguistically diverse communities [34]. However, the same study articulates that health literacy rates among migrants are prone to be misrepresented due to limitations in measuring practices which show bias towards those with high English speaking proficiency.

Several limitations should be considered. Selection bias may have occurred in the recruitment of participants as most participants had strong educational upbringing and were keen to participate in research important to their communities. In addition, at the recruitment phase of the project we may have missed a good proportion of the community who were unable to access radio programs and were possibly older. However, they were still lacking in many aspects of Vitamin D exposure and so our results may under-represent a greater problem in the wider sub-Saharan African male community.

\section{Conclusion}

Our findings contribute to new data on views of dietary awareness of vitamin D post migration, Muslim African men's masculine ideologies and gaps in health promotion and education of subSaharan African men in general. The implication of these findings are important for health planning of resources to such at-risk groups of men to support these men to make informed choices about diet and lifestyle implications on vitamin D deficiency. Being aware of these barriers and avoidance strategies common in men from these groups can aid policy planners at the level of local health planning to better engage these groups in the decision-making of vitamin $\mathrm{D}$ health strategies.

\section{References}

1. Martin CA, Gowda U, Renzaho AM (2016) The prevalence of vitamin D deficiency among dark-skinned populations according to their stage of migration and region of birth: A meta-analysis. Nutrition 32: 21-32.

2. Holick MF, Binkley NC, Bischoff-Ferrari HA, Gordon CM, Hanley DA, et al (2011) Evaluation, treatment, and prevention of vitamin D deficiency: an Endocrine Society clinical practice guideline. J Clin Endocrinol Metab 96 1911-1930.

3. Bikle DD (2014) Vitamin D metabolism, mechanism of action, and clinical applications. Chem Biol 21: 319-329.

4. Giovannucci E, Liu Y, Hollis BW, Rimm EB (2008) A prospective study of 25-Hydroxy-Vitamin D and risk of myocardial infarction in men. Arch Intern Med 168: 1174-1180

5. Berridge MJ (2017) Vitamin D deficiency and diabetes. Biochem J 474: 1321 1332.

6. Rukin NJ, Zeegers MP, Ramachandran S, Luscombe CJ, Liu S, et al. (2007) A comparison of sunlight exposure in men with prostate cancer and basal cell carcinoma. Br J Cancer 96: 523.

7. Anglin RE, Samaan Z, Walter SD, McDonald SD (2013) Vitamin D deficiency and depression in adults: systematic review and meta-analysis. $\mathrm{Br} \mathrm{J}$ Psychiatry 202: 100-107.

8. Scientific advisory committee on nutrition SACN. Vitamin D and health. U.K scientific advisory committee on nutrition.

9. Patel JV, Chackathayil J, Hughes EA, Webster C, Lip GY, et al. (2013)
Vitamin D deficiency amongst minority ethnic groups in the UK: a cross sectional study. Int J Cardiol 167: 2172-2176.

10. (2018) Australian Bureau of Statistics. 3412.0 - Migration, Australia, 2016-17.

11. Pereira CA, Larder N, Somerset S (2010) Food acquisition habits in a group of African refugees recently settled in Australia. Health Place 16: 934-941.

12. Renzaho AM, Burns C (2006) Post-migration food habits of sub-Saharan African migrants in Victoria: A cross-sectional study. Nutrition Dietetics 63: 91-102.

13. Wilson A, Renzaho AM, McCabe M, Swinburn B (2010) Towards understanding the new food environment for refugees from the Horn of Africa in Australia. Health Place 16: 969-976.

14. Renzaho A (2009) Challenges of negotiating obesity-related findings with African migrants in Australia: Lessons learnt from the African Migrant Capacity Building and Performance Appraisal Project. Nutr Dietetics 66: 145-150.

15. Saunders M, Peerson A (2009) Australia's national men's health policy: masculinity matters. Health Promot J Austr 20: 92-97.

16. Benitez-Aguirre PZ, Wood NJ, Biesheuvel C, Moreira C, Munns CF (2009) The natural history of vitamin $D$ deficiency in African refugees living in Sydney. Med J Aust 190: 426-428.

17. Brand CA, Abi HY, Couch DE, Vindigni A, Wark JD (2008) Vitamin D deficiency: a study of community beliefs among dark skinned and veiled people. Int J Rheum Dis 11: 15-23.

18. McGillivray G, Skull SA, Davie G, Kofoed SE, Frydenberg A, et al. (2007) High prevalence of asymptomatic vitamin $D$ and iron deficiency in East African immigrant children and adolescents living in a temperate climate. Arch Dis Child 92: 1088-1093.

19. Pirrone A, Capetola T, Riggs E, Renzaho A (2013) Vitamin D deficiency awareness among African migrant women residing in high-rise public housing in Melbourne, Australia: a qualitative study. Asia Pac J Clin Nutr 22: 292-299.

20. Renzaho A, Green J, Mellor D, Swinburn B (2011) Parenting, family functioning and lifestyle in a new culture: the case of African migrants in Melbourne, Victoria, Australia. Child Fam Soc Work 16: 228-240.

21. Skull SA, Ngeow JY, Biggs BA, Street A, Ebeling PR (2003) Vitamin D deficiency is common and unrecognized among recently arrived adult immigrants from The Horn of Africa. Int Med J 33: 47-51.

22. Reiner A (2010) Background paper for African Australians: A review of human rights and social inclusion issues. Australian Human Rights Commission $1-72$.

23. Tiedje K, Wieland ML, Meiers SJ, Mohamed AA, Formea CM, et al. (2014) A focus group study of healthy eating knowledge, practices, and barriers among adult and adolescent immigrants and refugees in the United States. Int J Behav Nutr Phys Act 11: 63.

24. Garfield CF, Isacco A, Rogers TE (2008) A Review of Men's Health and Masculinity. Am J Lifestyle Med 2: 474-487.

25. Ritchie J, Spencer L (2002) Qualitative data analysis for applied policy research. The qualitative researcher's companion 573: 305-329.

26. Cha E, Yang K, Lee J, Min J, Kim KH, Dunbar SB, et al. (2012) Understanding cultural issues in the diabetes self-management behaviors of Korean immigrants. Diabetes Educ 38: 835-844.

27. Cason K, Nieto-Montenegro S, Chavez-Martinez A (2006) Food choices, food sufficiency practices, and nutrition education needs of Hispanic migrant workers in Pennsylvania. Top Clin Nutr 21: 145-158.

28. Department of Health and Ageing (2010) National Male Health Policy: Building on the strengths of Australian males. Australian Government 1-40.

29. Courtenay WH (2003) Key determinants of the health and well-being of men and boys. Int J Mens Health 2: 1.

30. Addis ME, Mahalik JR (2003) Men, masculinity, and the contexts of help seeking. Am Psychol 58: 5-14.

31. Lane JM, Addis ME (2005) Male gender role conflict and patterns of help 
Citation: Hassan A, Wollersheim D, Susanto NH, Batra M, Itsiopoulos C, et al. Dietary Vitamin D Knowledge of Sub-Saharan African Men Who Migrate to Australia. J Nutri Health. 2018;4(2): 4.

\section{ISSN: 2469-4185}

seeking in Costa Rica and the United States. Psychol Men Masc 6: 155-168.

32. Alemu E, Varnam R (2012) Awareness of vitamin D deficiency among at-risk patients. BMC Res Notes 5: 17
33. Sheikh-Mohammed M, Macintyre CR, Wood NJ, Leask J, Isaacs D (2006) Barriers to access to health care for newly resettled sub-Saharan refugees in Australia. Med J Aust 185: 594-597.

34. Garad R, Waycott L (2015) The role of health literacy in reducing health disparities in rural CaLD communities. $13^{\text {th }}$ National Rural Health Conference. 